\title{
Business model options for passenger urban air mobility
}

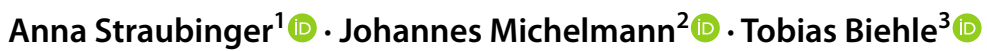

Received: 1 December 2020 / Revised: 23 February 2021 / Accepted: 31 March 2021 / Published online: 9 April 2021

(c) Deutsches Zentrum für Luft- und Raumfahrt e.V. 2021

\begin{abstract}
While technological progress towards passenger urban air mobility (UAM) receives high attention, relevant business models for the deployment of these increasingly sophisticated passenger-carrying air vehicles for urban applications get less attention. However, especially in early market stages with high risks of investment and in respect to an often envisioned implementation of transport services in the proximity of urban settlements, it is important that the technology adds value to society. In this paper relevant perspectives to comprehend the current UAM business environment are presented. Possible operator models and customer segments are compiled and matched in three concrete business model approaches for passenger UAM. Scrutinising UAM Airport Shuttle Services shows that even concepts with sufficient demand might still not be adequate for a valid business case due to incomplete and a so far insufficient critical analysis of the overall operational environment. Second, a so far often unconsidered business model for a Company Shuttle Service is introduced, addressing the problem of scaling up UAM services with a dynamically expandable Business-to-Business (B2B) concept. Third, UAM will be discussed as part of public transport, introducing a business model that is inclusive and in strong line with public demands. Finally, these rather different implementation concepts unlock the space for an open-minded discussion on business models in the field of passenger UAM in general.
\end{abstract}

Keywords Urban air mobility $\cdot$ Business models $\cdot$ Airport shuttle $\cdot$ Company shuttle $\cdot$ Public transportation

$\begin{array}{ll}\text { Abbreviations } \\ \text { ATC } & \text { Air traffic control } \\ \text { B2B } & \text { Business-to-business } \\ \text { B2C } & \text { Business-to-consumer } \\ \text { CTR } & \text { Controlled airspace } \\ \text { ICAO } & \text { International Civil Aviation Organisation } \\ \text { IFR } & \text { Instrument flight rules } \\ \text { KPI } & \text { Key performance indicator } \\ \text { MaaS } & \text { Mobility as a service } \\ \text { MRO } & \text { Maintenance, repair and overhaul } \\ \text { OEM } & \text { Original equipment manufacturer } \\ \text { O\&D } & \text { Origin and destination }\end{array}$

Anna Straubinger

Anna.Straubinger@bauhaus-luftfahrt.net

Johannes Michelmann

johannes.michelmann@tum.de

Tobias Biehle

tobias.biehle@tu-berlin.de

1 Bauhaus Luftfahrt e.V., 82024 Taufkirchen, Germany

2 Technical University of Munich, 85748 Garching b. Muenchen, Germany

3 Technical University of Berlin, 10587 Berlin, Germany
SESAR Single European sky ATM research programme UAM Urban air mobility

UAS Unmanned aerial system

UTM UAS management

VTOL Vertical take-off and landing

\section{Introduction}

In recent years, enhancements in distributed and electric propulsion have led to a technology push in the drone sector, and have triggered developments towards passengercarrying aerial vehicles for civil use in urban settings [2]. Although urban aerial mobility has been a minor part of the transport landscape for decades by deploying helicopters, various novel concepts of mostly electrical vertical take-off and landing (VTOL) vehicles now offer advancements that promise to dramatically expand that market and to provide a relevant mode of transport for people over short to medium distances. The realisation of commercial and VTOL-based passenger Urban Air Mobility (UAM), however, makes it necessary to intensely consider economically viable application scenarios, which at the same time address actual 
demands for transportation in society. Following an economic perspective, this paper is scrutinising on three differing business models and at the same time is contributing towards a critical, open-minded and value-led development of UAM.

Research on business models in the field is rather novel, therefore sparse references can be cited. Standards, however, can be derived referring to academic work in the field of electric, shared and autonomous mobility [3-5]. Following Osterwalder and Pigneur [5] we define a business model as a conceptual tool that enables an understanding of a business with regard to management, communication and innovation. Osterwalder and Pigneur's [6] business model canvas is used as a conceptual tool to structure the assessment of the business models presented in this paper [6].

The following Sect. 2 introduces the readership to the technology innovation and the capabilities for passenger transportation that can be derived from it. Next, the system environment is scoped in which the UAM vehicle must be operated for commercial applications. In the following, central technical, infrastructural and societal barriers are discussed that currently impede a large-scale introduction of services. Having created that basic understanding of contextual factors this paper will focus explicitly on relevant economic considerations made in respect to passenger Urban Air Mobility (Sect. 3). Reflections on the UAM market stated in academic and private sector literature will be reviewed. Potential customer segments and operator models are compiled from existing literature as well as private sector statements and discussed in respect to value propositions and key resources respectively. Three business model approaches are derived and analysed. Seeking to qualify and to enrich research on UAM business models we assess: (1) an airline offering an airport shuttle with UAM vehicles, (2) an alliance of private companies operating UAM services as a linkage between their premises, and (3) a public transport provider offering rural-urban connection through UAM services to the general public in Sect. 4. Finally, the identified business models will be discussed regarding their validity, targeting on key attributes and possible showstoppers for each business model. The paper concludes by summarizing the findings and gives insight into future work (Sect. 5).

\section{Basis for passenger urban air mobility}

VTOL vehicles continuously prove their suitability for a wide range of different applications. Besides services for sensor and communication tasks currently being of large significance, transport services for cargo and passengers continuously gain relevance as novel aircraft concepts are promised to bring aerial mobility into urban space while being quiet, energy efficient and safe. While these claims have yet to be proven within concrete application scenarios [7], UAM is strongly pushed by continued technological progress [8].

\subsection{System configurations and operating environment for passenger UAM}

While companies from several backgrounds are working on UAM vehicles, contrary to e.g., automotive or classical aviation, where vehicles have similar basic designs, this novel field has not converged towards a dominant vehicle framework concept. Even when considering eVTOL vehicless only, a broad range of configurations is being developed. Shamiyeh et al. [1] discuss the advantages and limitations of these currently prevailing concepts. A key element in the consideration of suitable design for the respective application scenario is the demand for either energy-efficient cruising (e.g., fixed wings) on long distances or the need for space-efficient vertical take-off and landing (rotary wings) in inner city application (See Fig. 1).

Following the work of Straubinger et al. [8] the vehicle's specifications are embedded and reflected within a complex system environment that may allow for the introduction of commercial UAM service. Depending on the precise business model, various shareholders along the revenue stream of the transportation service must be considered (Table 1). In return, however, market actors are offered the possibility to integrate in multiple sub-markets simultaneously allowing for a broader revenue stream. In this context, each potential UAM operator has its own key resources as well as limitations.

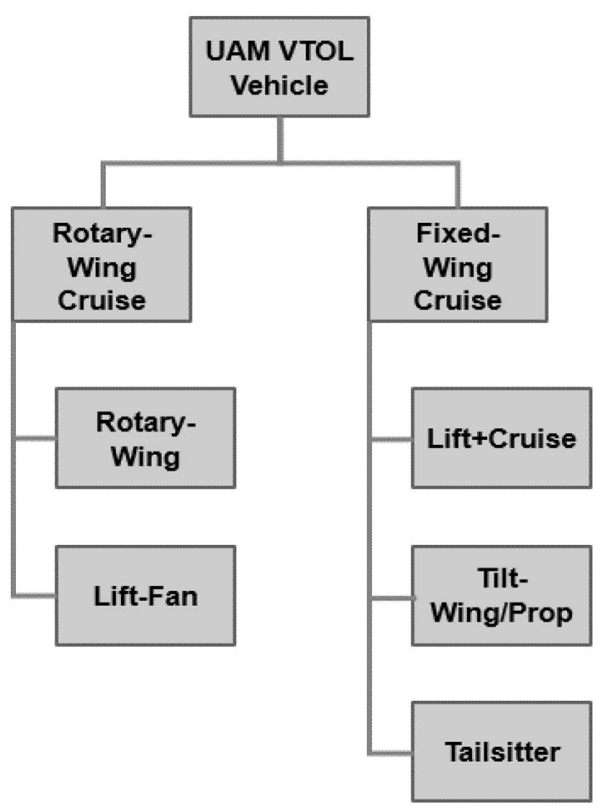

Fig. 1 Overview over VTOL vehicle configurations [1] 
Table 1 Relevant UAM system shareholders (adapted from [8].)

UAM system shareholders

Vehicle owner

Vehicle manufacturer

Ground infrastructure provider

Platform provider for consumer communication

Insurance provider

Service provider for flight scheduling and planning

Provider for air navigation and ATM at low altitude

Communication and data infrastructure provider

Maintenance, repair and overhaul (MRO)

\subsection{Current challenges and anticipated barriers to passenger UAM}

To assess business models for UAM services, relevant framework conditions must be considered. In the following, we depict the main barriers to commercial aspirations in the fields of technology, infrastructure and social acceptance.

\subsubsection{Technical challenges}

Advances in distributed electric propulsion seem to promise a whole new future taking aerial mobility into the urban settlement with less energy consumption and lower noise footprints. Yet, especially regarding propulsion technologies drastic improvements are still required. While relevant systems are under development and partially available today, they account for high research, certification and production costs. It can thus be assumed that the more such systems are obligatory for operation, the more mature a business concept must be to cover these costs.

Batteries: As shown by Shamiyeh et al. [1] electric VTOL vehicles concepts often face strict limits with regard to range that are mainly driven through limits in energy density of current batteries. Therefore, hybrid-electric vehicle configurations are of interest to many vehicle manufacturers.

Propulsion: In addition to that, advancements regarding noise are important to gain public acceptance for UAM in densely populated areas. The main driver of noise for VTOL vehicles is the blade tip speed, which can be reduced through large disc areas of multicopter configurations [2]. Additional drivers are the number of rotors as well as the specific rotor design and corresponding shielding mechanisms.

Automation: Further barriers for commercial UAM deployment lie in requirements regarding automation degrees and in navigation and communication technologies to significantly reduce personnel costs. Anticipating many vehicles operating over a small area and under various weather conditions, new technologies for conflict detection and avoidance need to be developed and implemented.
Further requirements regarding means of communication with Air Traffic Control (ATC) and precise navigation arise for applications requiring interference with commercial aviation and airports [9-11].

\subsubsection{Infrastructure}

When talking about UAM services, different types of infrastructure are required. While there is a shared private and public interest to expand relevant data and telecommunication infrastructure, the development of UAM ground infrastructure and Unmanned Aerial Systems (UAS) and UAS Traffic Management (UTM) cannot be expected to be driven by other markets.

Ground infrastructure: Often low infrastructure demand is named a key advantage of UAM and first discussions around UAM were often based on ideas of flying cars that would not require dedicated infrastructure. Yet, the need for facilities for take-off and landing, to handle passengers (e.g., security check, bathrooms) and to refuel, charge or maintain the vehicle, demand for dedicated infrastructure. So far, only a little research has been conducted in the area of vertiport design and regulations do not exist yet. Vascik and Hansman [12] show first layout options for vertiports but have little chance to look far beyond the lines of helicopter landing areas.

A brief example shows that vertiports could be one of the main capacity restricting and cost-driving aspects of UAM: Looking at a city like Berlin and assuming a UAM modeshare of only $1 \%$ with three daily trips per person already leads to a demand of 114,000 UAM trips per day within the city. Assuming further an occupancy rate of four passengers per vehicle leads to a minimum of 28,500 take-offs and 28,500 landings per day. Distributing these trips evenly over 16 operating hours a day leaves 3560 vehicle movements (take-offs and landings) per hour. Assuming that a landing pad is blocked for $60 \mathrm{~s}$ per vehicle movement, a total of 60 landing pads is required within the service area. These calculations indicate the lower boundary for infrastructure demand, as demand is assumed to be spread evenly across space and time. Providing infrastructure to serve this demand can and will be a challenge especially in regions where land is sparse and planning durations for infrastructure are long and expensive [13].

UTM infrastructure: The need to set up a UTM system is a pressing task for commercial UAM services, recognizing that large parts of traffic will take place in yet unregulated airspace. Discussions are currently evolving around different organizational set-ups (central vs. decentral), safety bounds and remote identification (e.g., Mueller et al. [14], Geister \& Korn [15]). In the literature examined, there are numerous aspects of how the design of such a UTM system will influence the economic exploitation of VTOL-based 
transportation. A central topic is the question of how to deal with the limited capacities of airspace which exist today already for manned aviation. Especially at the interfaces to lower airspace in urban conurbations, unmanned aerial vehicles will additionally compete for airspace access [16]. Competition in lower airspace itself already poses risks for operational procedures as the economical exploitation of transport drones may depend on"regulators' ad hoc decisions about who receives airspace and terminal access during times of congestion" [17]. Groundings or operational delays are considered critical since time saving represents one of the key assets of the technology, especially in competition with ground-based passenger transport [18].

\subsubsection{Acceptance and adoption}

In market research $[19,20]$, in strategy and policy papers [21], as well as in scientific research publications [22, 23], existing acceptance is cited a prerequisite for UAM to be deployed on an economically viable scale in the future. From a social science perspective, two approaches towards acceptance must be distinguished. One considers the socio-political attitude towards tolerating or approving the technology to be used in public space. The second perspective focuses on whether potential customers are willing to actively choose UAM as their mode of transportation, which we will call passenger adoption in the following. Indeed, as UAM is not yet tangible neither to the public nor to customers, predictions are difficult to make [24, 25]. However, research efforts are essential to identify the criteria by which the technology and the services must be designed in terms of its societal value as well as its convenience for customers [26].

Societal acceptance: It will be a characteristic of UAM that far less people will actively use such services than those who will be passively exposed to the possible negative implications of urban airspace use $[27,28]$. Foremost to name in this context are the additional security and safety risks posed by UAM. Concerns about increased noise levels and privacy invasion are also persistent in the relevant literature [7] as well as proven significant acceptance factors in representative surveys [29]. Additionally, decreasing urban life quality due to traffic movement in the sky $[30,31]$, stress effects on people and the animal fauna [32], land-use conflicts due to infrastructure demand as well as the public rejection of a new form of elite mobility [33] may lead to the (urban) population exercising its "stake" on UAM introduction.

User adoption: With regard to user acceptance, $\mathrm{Al}$ Haddad et al. [34] have conducted an empirical study on which factors the willingness to use UAM depends on. In respect to existing research they confirmed the influence of the user sense of security towards UAM and the perceived trustworthiness of the service provider. Further decision factors are the expected reduction of the individuals travel time, the estimated reliability of the offered service and the user perception of automation costs. Also shown to be relevant were the potential user attitude towards automation, data security as well as demographic characteristics of the respondents [34]. Studies further stress on the importance of the availability (e.g., in the form of on-demand services), the costs and the accessibility of the service (e.g., the distribution and accessibility of vertiports). Additionally, the comfort in booking, execution and handling of the flight, the comfort during the flight (e.g., the possibility to use the travel time for entertainment or productive activities) as well as the quality of the physical flight $[35,36]$ are considered.

As UAM services are new to customers and as VTOL vehicles operate in public always, both user adoption and societal acceptance pose major challenges, that require to be tackled in the development of the respective business models and operating concepts.

\section{Passenger UAM business environment}

The explanations up to this point provide an understanding of the contextual factors under which future UAM business models must be proven valid. The following section will now provide economic perspectives and stresses the strategic challenges the current passenger UAM market is facing, the demand and target groups addressed within this market and which actors, based on resources and strategic position, are able to meet this demand.

\subsection{Economics of passenger UAM in the literature}

Opening lower airspace for economic exploitation is expected to provide a considerable impetus for academia, technology development and economic growth $[37,38]$ in both the military and civil sector [39]. Current key drivers for the civil market are commercial drone applications in sensor technology and communication, however, the market size for passenger carrying VTOL vehicles and related services is considered to excel its value in the long term [40]. In future, the biggest share of profits is considered by brokering Mobility as a Service (MaaS) solutions [41].

Market perspectives: An economically crucial point is seen at the technology's maturation from the level of demonstration into a mass market, allowing for economies of scale and for significantly lower production cost [42]. Mass air transit is expected to become affordable for larger parts of society in the long term only owing to further computation advancements, leading to autonomous operations [17]. Further hesitations may evolve if "the market is not mature enough to identify a clear demand within the civil sector" [31]. Rao et al. [43] state that the economic success of UAM is dependent on "the ability of varied stakeholders 
to reconsider how this emerging technology platform can be best harnessed to serve the broad interests of society" [43], urging for a value-led development of UAM services.

Utilisation capabilities: A consolidation of how commercial UAM services will evolve has not yet begun. Consultancies, like e.g., Roland Berger [20] see airport shuttle, innercity air taxi and inter-city connections as its most promising use cases. Looking at the different studies on the modal share of UAM in overall traffic, none exceeds a maximum share of 4\% [44-46].

Hansman and Vascik [47] name daily or weekly commute scenarios and discuss non-commute point-to-point as well as non-transportation missions, e.g., sightseeing. They further reflect on possible operational models such as private air transport, personal scheduled transportation, personal unscheduled transportation (on-demand mobility) and commercial scheduled transportation. Nneji et al. [48] present ownership options and distinguish between Personal Air Vehicles ownership options (i.e., centralized, decentralized, and self-ownership) and operational models (i.e., professional operator and self-operator).

\subsection{Potential customer segments of passenger UAM}

The development of meaningful business models requires a clear understanding of the needs of people that shall be addressed by a product or service. Conceptual approaches in regard to passenger UAM come from Straubinger et al. [49], building on work of Kluge et al. [50]. Five traveller types have been identified and characterised as predominant UAM adopters: The Digital Native Business Traveller covers the group of reasonably young and technology-savvy passengers that travel alone or in small groups and have an above-average income. The Family and Holiday Travellers belong to the same income group, yet they travel in larger groups with their families, which leads to different expectations towards the transport service. The Single Traveller and the Cultural Seeker both travel alone or in small groups and might use UAM for special occasions.

Altogether this emphasises on a broader definition of customer segments that have a strong focus on trip purposes whereby the UAM trip either answers the full transport demand or is part of a longer travel chain that might also include conventional air or ground travel. Table 2 presents a comprehensive listing of potential customer segments retrieved from both the quoted literature as well as from own considerations, which will be discussed in respect to the value added to each customer segment.

\subsection{Potential operators of passenger UAM}

Stressing the current debate on UAM operation, the focus clearly is on the cross-operator challenge on defining the certification criteria that will allow eligible applicants to manage and "pilot" VTOL vehicless for UAM services in future. In addition to the necessity to meet these criteria, applicants may have varying assets that become relevant for an economically viable UAM operation and that allow for different levels of vertical integration into the sub-markets. To our knowledge, however, a comprehensive discussion of the strengths and weaknesses of possible UAM operators under economic considerations has not yet taken place. Possible operator models and their characteristics must therefore be derived from general considerations in the literature and from stakeholders who already articulated their interest in becoming a UAM Operator. Table 3 provides a comprehensive but not exhaustive list.

\section{Business model options}

Combining both substantive and conceptual remarks up to this point now allows for the comprehensive assessment of the three passenger UAM business models presented in this paper:

- Airport shuttles;

- Company shuttle;

- Regional public transport shuttle.

The choice of these models was driven by several factors, the most important being the goal to present potentials and obstacles of UAM, especially in its introduction phase. The airline-operated UAM airport shuttle was chosen to contribute to a more fact-based and critical discussion of a currently often-advertised concept, showing that an expectable sufficient demand might still not make up for a valid business case. With the privately-operated Company Shuttle Service, a so far undescribed business model is presented, proving the existence of room for innovative ideas in the field of UAM. By scrutinising on a Regional Transportation Service through a Public Transport Provider the possibilities of a more value-led development through the means of UAM introduction are presented.

\subsection{Airport access shuttle through airlines}

As depicted by Reichmuth et al. [51], "Airport accessibility is a key factor in airport choice." The most common means of landside airport access is by car, followed by public transport, including railway access modes [51]. Currently, many airports around the world face problems regarding long landside access times for O\&D (origin and destination) passengers. Sources for these difficulties can be manifoldmay they be long distances between an airport and the main urban centre it serves, inadequate accessibility by means of 


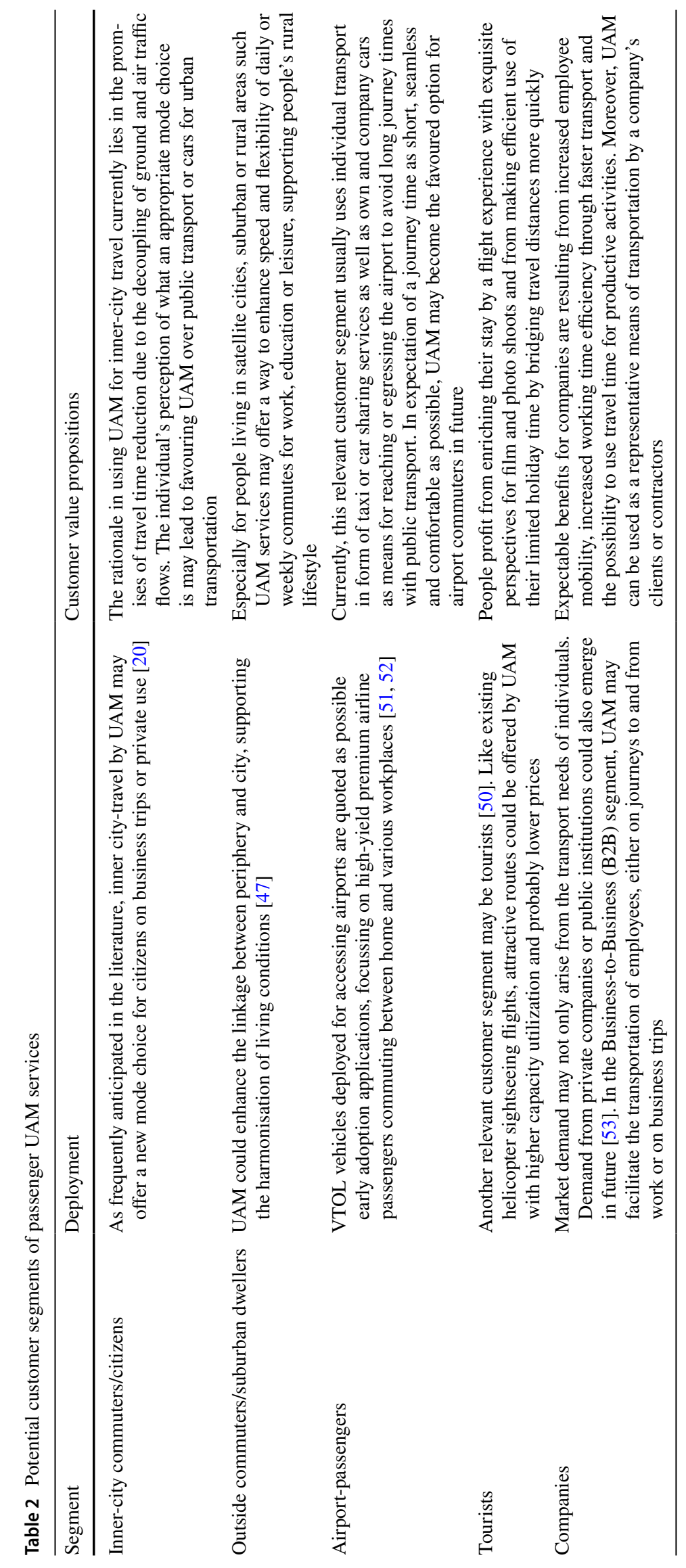




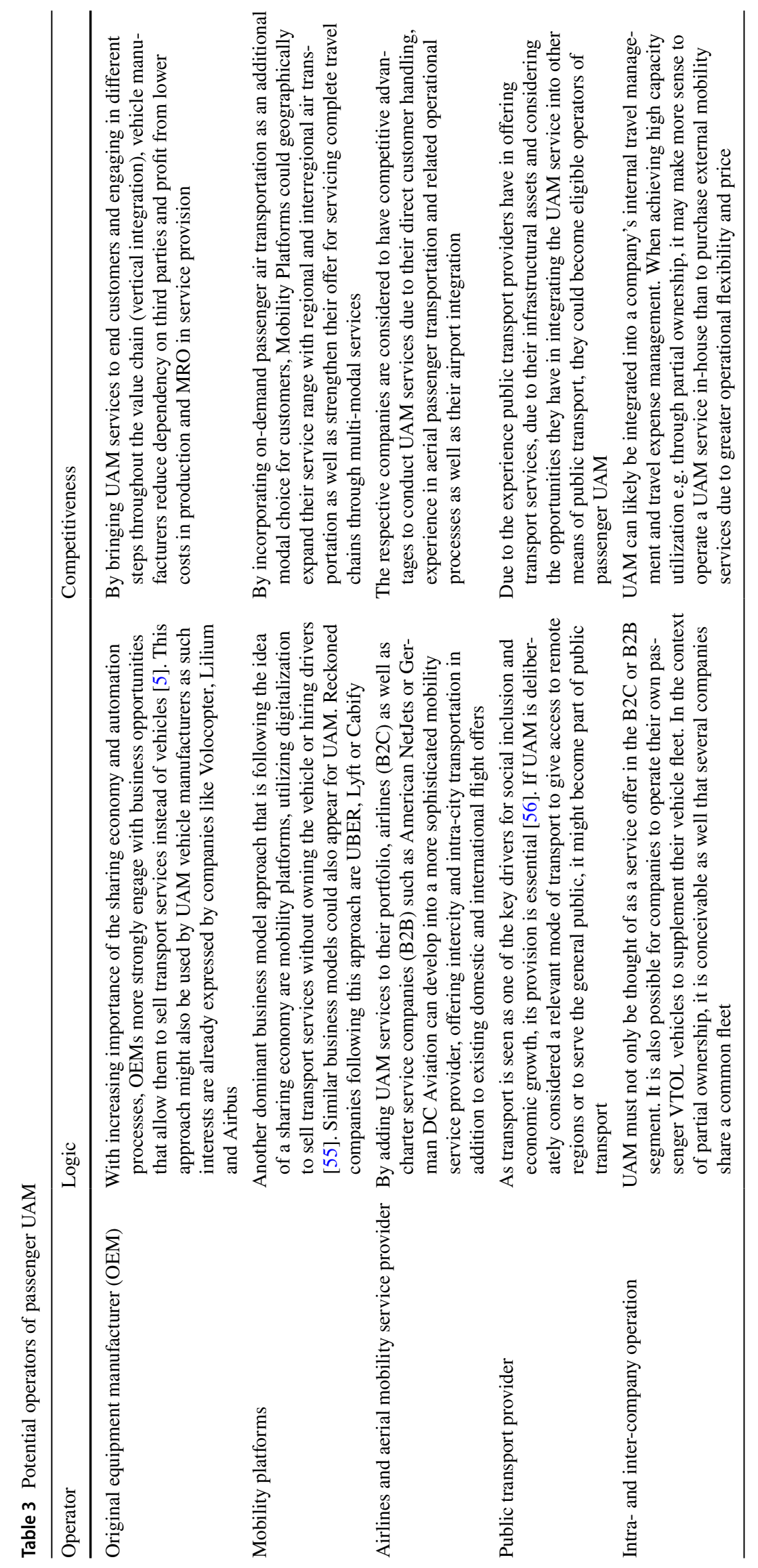


public transport or congestion on the landside access routes, or even combinations of all of these factors. Therefore, airlines utilizing such airports as key nodes in their network might seek solutions to eliminate these problems and related competitive disadvantages compared to other airlines using better accessible airports in the near vicinity. Examples for airlines having identified this problem and trying to solve it can be found in cooperation with railway companies offering free airport access tickets (see Reichmuth et al. [51]). Recently, UAM is often mentioned as an opportunity for fast travel between the airport and urban centres [19, 54], which might trigger an airline's interest in such a system. Possible advantages are low vulnerability to traffic jams, fast travel times and easy integration into the urban space due to low space requirements for vertiports.

Therefore, the goal of such a service is to add a further means of last-mile-transport for air passengers with the two main goals of lower travel times and increased comfort. Due to low passenger capacities, such a system would operate complementary to existing public means of transport and in competition to individual transport (e.g., taxi services, see Porsche Consulting [19]).

The described expectations require a transport system able to operate reliably in all weather conditions. Accessibility to the airport for the VTOL vehicles has to be assured in the most direct form possible, preferably with the access vertiport being not further away from the terminal than access points for competing means of transports (e.g., taxis) to avoid the necessity of a change of the means of transport before reaching the airport. The last assumption would require the vertiport to be integrated into the terminal infrastructure.

Recently, there have been various suggestions for possibilities for the introduction of such UAM airport shuttle services. Examples include a cooperation between Volocopter and Fraport, the operator of Germany's most important hub airport [57], as well as vague plans for such a service between the central train station of Munich and Munich airport [19]. In the following, we will point out challenges for the introduction of UAM as airport shuttle services and thereby focus mainly on airspace and airport operationrelated issues.

\subsubsection{Airport shuttle business model}

In the following, we present the business model envisioned for UAM Airport Shuttle services in more detail.

4.1.1.1 Customer segment The main customer group are airline passengers transiting between the airport and their origin or final destination. Prices are expected to be rather high and above those for taxi rides. The shuttle service primarily targets high-income premium passengers travelling in first and business class, therefore mainly business travellers.

4.1.1.2 Value proposition The by far most important key driver for these passengers to use UAM airport shuttles is time saving as compared to current means of transport (see e.g., Fu et al. [58]). This is interesting to individual persons as well as companies requiring faster airport access for facilitating business trips. A second field of customers might be attracted by the feeling of using an unusual, premium transport service, conveying a sense of status.

Further key customer expectations include the provision of a seamless travel experience, requiring the transfers between different means of transport to be kept at a minimum. Such transfers include inconveniences in the form of additional waiting times, carrying of luggage [51] and disturbance in work the passenger might want to accomplish while travelling. In contrast, price will not play an essential role as a decision variable for the passenger, considering the envisioned customer segment.

An airline implementing such a service in its portfolio might have a competitive advantage by offering new premium services for its customers and shortening their travel times. Airlines in general have advantages in offering UAM airport shuttle services since they possess aviation-specific resources and know-how facilitating the introduction and operation of airborne services in general, especially relevant in the introductory phase of UAM. This will be shown in more detail below.

4.1.1.3 Channels The service would be easy to integrate into the airline's flight booking process as a further ancillary source. No new channels have to be opened to access an already existing customer base. The UAM shuttle service would be offered as a supplementary element during the flight booking process, enhancing possibilities for passengers for door-to-door travel. Spontaneous last minute bookings can be conducted with the flight attendants and via the on-board entertainment system aboard the airline's flights.

4.1.1.4 Customer relationship Customers are the airline's passengers (individual and staff from entire companies). Contact is established via virtual (booking website) and personal (flight attendants) services. However, like with the services offered by airlines today, direct contacts with the customer will be limited to a minimum.

4.1.1.5 Key resources A high utilization on vehicle as well as fleet level is required for maximum revenue generation. This can only be accomplished via sophisticated operational procedures that an airline certainly can provide. This leads to the assumption that an airline might be an optimal operator for UAM airport shuttle services because it is able to effi- 
ciently handle different elements of a cost structure, which is in many ways similar to the one of conventional aviation. Further examples for the latter may include:

- Experience in maintenance of complex aircraft engines and systems;

- Experience in dealing with aviation standards and certifications (also applicable for UAM);

- Staff basis qualified to conduct aviation related tasks and processes.

As mentioned above, the main customers for a UAM airport shuttle service are airline passengers. In this regard, airlines have a significant advantage as UAM operators due to providing the customer base for the shuttle service themselves by already having access to these customers. Furthermore, airlines already implemented the main distribution channel in the form of flight booking websites. Due to the abovementioned high costs being expected during the introduction of this new means of transport and a limited vehicle availability at this phase, operators can offer capacities that are sufficient for a use as individual transport only.

4.1.1.6 Key activity The airlines operating such a system would plan, advertise, sell and operate the flights themselves, while also conducting MRO inhouse. Airport vertiports are operated in cooperation with the airport, all other vertiports in cooperation with local authorities and companies. However, airlines will mostly be responsible for the airside operations at all vertiports. Still, promoting the service advantage and acquiring new companies as customers is an essential task in marketing the new service.

4.1.1.7 Key partners Airports as well as local authorities need to permit the operation of UAM flights and vertiports on their terrain. The airline has to cooperate with both as well as with ATC in order not to impair conventional air traffic and to gain all necessary operating allowances and certifications. This counts especially since there are currently no certification standards or regulations available, e.g., for the integration of UAM into the airspace (see Sect. 4.1.2). Airports might as well try to participate in the operation of UAM to improve their attractiveness for and accessibility to customers. Companies searching for faster access to the airport can also act as cooperation partners.

Cooperation with airports is further required for building up the required ground infrastructure at or near the airports. Similar cooperation might exist for example with public transport providers to build up the necessary vertiports in residential areas. Such a cooperation would have synergies owing to better connectivity to the local transport infrastructure. Passengers would start their journey either from company grounds or from a local transport hub, which is easily accessible by means of first mile transport to reduce travel times.

4.1.1.8 Cost structure This business model is often seen as an initial use case for UAM by literature as described above. Especially at the beginning of UAM operations experience with the new technology is rather limited. Investments are expected to be high into the required infrastructure on the one hand and into building up a fleet of vehicles on the other hand. The latter is connected with introducing a new product relying on probably expensive technology and not being mass-produced in the early stages of market entry. Furthermore, the operation of such expensive vehicles will presumably be driven by high direct operating costs. These include maintenance work, personnel costs, energy provision, insurance, cleaning, ATC and landing fees, salaries, noise charges, depreciation costs and many more. Further costs in the operation of the airport shuttle might arise at the landing sites near or at the airport. Currently, the target group of the shuttle service is expected to often arrive at the airport by different means of individual transport, e.g., private or company cars, rather than public transport [50, 51]. Related airport parking fees contribute part to the non-aviation revenues of the airport. In case these customers arrive at the airport by UAM services, the airport might similarly seek to charge each UAM movement.

4.1.1.9 Revenue streams The main value of a UAM airport shuttle service for the operator is opening a new source for ancillary revenues by diversifying the offers for its customers. Having access/egress as part of the airline's service also facilitates passenger-centred approaches to access and egress in case of flight delays. To cover costs, revenues per passenger need to be high compared to public transport. Another reason for high prices are low passenger transport capacities during the introduction phase, while costs are still high shortly after service introduction. Therefore, ticket prices in the range of or higher than current taxi services are to be expected which under the mentioned circumstances addresses premium (first and business class) passengers mainly.

\subsubsection{Discussion}

Although the above-mentioned points might indicate a valid business model for UAM airport shuttles with sufficient customer demand, there are further hurdles for this concept. As an example for the necessity of analysing the entire system environment to develop valid UAM operational models, the implications of UAM integration into the controlled airspace (CTR) around and at airports based on available regulatory concepts of similar vehicles will be discussed. As shown by BoozAllenHamilton [56], a majority of UAM operations 
in urban centres might take place in controlled airspace, exceeding capacities of air traffic control. While the nearterm introduction of new control technologies (e.g., UTM) seems questionable, there are further limitations arising for operations near airports, challenging UAM. UAM will be evaluated regarding airport accessibility and considering competing means of transport. Thereby, key factors for UAM infrastructure integration at airports are derived.

4.1.2.1 Requirements and basic regulations A seamless journey with short travel times for a UAM airport shuttle service requires a landing site as near as possible to the airport terminal. This automatically implies flights of UAM vehicles through the CTR at and around airports. These operations become most sensible when taking place near runways as well as approach and departure paths. Less sensible are operations in the CTR not influencing the airport's runway. To guarantee reliable services, UAM must be able to fly under most weather conditions, necessitating flights after instrument flight rules (IFR). As to the knowledge of the authors, there are currently no regulations under development specifically designed for the integration of UAM into airspace. However, orientation can be given by technical and regulatory novelties in similar fields like UAS operations. UAS are currently subject to the regulations valid for conventional manned aircraft, especially ICAO Doc 4444 [59]. No specific regulation for UAS integration into current airspace is implemented [60], however, concepts for future regulation can be found in the U-space Blueprint [61] and for UTM concepts in Mueller et al. [14] or the Concepts of Operations v2.0 for UTM of FAA [62]. Currently, IFR flights of UAS cannot be conducted and UAS operations within distances from airports in the range of a few kilometers are not yet recognized (SERA) [60, 63, 64] Although concepts for UAS integration within controlled airspace remain often vague, compare e.g., with [61], the four main requirements defined by ICAO give an orientation for necessary developments. According to these, UAS should have no significant impact on current users, comply with regulations for manned aviation and do not lead to an increase in risk for existing aviation. Furthermore, UAS operations shall be conducted in the same way as those of manned aircraft and seen as equivalent by ATC and other airspace users [64].

In case no further provisions are made, regulations of ICAO Doc 4444 [59] are in place as for manned aviation [60], following the goal that UAS "should conform to manned aircraft standards to the greatest extent possible" [9].

\subsubsection{UAM integration in air space at airports Accord-} ing to U-space, the integration of UAS into CTR requires amongst others high degrees of automation as well as sophisticated interfaces with ATC and conflict resolution tech- nologies $[9,60]$ When it comes to interfering with airport runway operations, the picture becomes more complex and vague regarding definitions in the available $\mathrm{U}$-space concept of operations. In general, UAS flights have to ensure unrestricted operations of existing stakeholders [59] and give way to manned flights $[9,60]$. Therefore, UAS have to comply with IFR/VFR (visual flight rules) rules the same way as conventional aircraft do and especially have to be able to follow common standard procedures for approaching and departing airports in IFR [64], implying that VTOL vehicles have to follow the wake turbulence separation requirements. This counts for approaches to a current runway as well as for dependent approaches parallel to the runway in a distance of less than $1035 \mathrm{~m}$ from the runway centreline [59]. Such an approach procedure would significantly reduce the capacity of the current runway system, due to VTOL vehicles replacing conventional aircraft in the approach sequence, the long separation minima for VTOL vehicles (wake turbulence category "Light"), and low approach speeds of VTOL vehicles as compared to conventional aircraft. Because of the small size of VTOL vehicles, the minimum distance between independent parallel approach paths for conventional aircraft and VTOL vehicles as well as the separation minima themselves might also need to be verified and enlarged [14], especially for unfavourable wind conditions.

Runway or approach path crossings might seem as a feasible alternative avoiding the integration of VTOL vehicles into the approach pattern. The only available document addressing this procedure is the UAS ATM Integration Operational Concept [64]. Such "sensitive" operations are envisioned to need pre-authorization and are only considered suitable for single events like emergency operations rather than constant activities [64]. Also note that in the case of approach path and runway/midfield crossings separation minima apply as well for different reasons, effectively limiting the runway capacity for conventional traffic [59].

4.1.2.3 Implications for UAM airport operations The above points mean that an integration of UAS and UAM into conventional airport runway operations is deemed possible at the price of massive losses in runway capacity for conventional aircraft. Any such reduction in runway capacity would contradict the ICAO requirements described above as well as the aerodrome Key Performance Indicators (KPI) defined by EUROCONTROL [64] and would be unacceptable to airlines and airports, which would both face limitations of their traffic performance and passenger numbers. Another possibility would be for VTOL vehicles to wait until a runway crossing is possible without interfering with other traffic. However, this would require long waiting times, especially at hub airports, effectively eliminating the time advantage of UAM journeys. Therefore, dependent parallel approaches or integration of VTOL vehicles into 
the conventional approach sequence of a runway as well as runway or approach path crossings are deemed unfeasible, implying that entering the highly sensible area of an airport runway or the respective approach and departure routes probably remain prohibited for VTOL vehicles even within future regulations. This is supported by the view described by EUROCONTROL [64] that operations of UAS at bottlenecks of the air transport system such as major airports and terminal airspace are not foreseeable. Accordingly, the authors of different U-space concept papers as well identify airports as sensitive sites with the need for protection [9], e.g., by geo-fencing [60]. This also holds true considering the introduction of high-accuracy positional location and tracking systems, e.g., Performance-Based Navigation as foreseen for Helicopter-RNP (Required Navigation Performance). In this case, separations might be reduced [60] but do not disappear. Higher runway capacities might therefore be possible; however, these might be required for additional conventional aircraft operations after the end of the COVID19 crisis when aviation returns to the projected air traffic growth (e.g., ICAO [65]). Finally, as EUROCONTROL [64] states, questions regarding the integration of UAS with wake turbulence separation minima have not been addressed so far.

All above-mentioned procedures basing on the U-space concept are not binding law and most of them are far from being implemented. It is therefore still questionable whether flights in controlled airspace will be possible for VTOL vehicles. According to EUROCONTROL [64] opening controlled airspace for a wide range of operations of UAS and UAM is not expected before 2027 + with $U$-space phase U3. According to SESAR [60], so-called type $Z$ airspace will be available with phase U3. Such airspace is expected to allow for the highest traffic density in very low airspace possible within U-space by offering both strategic and tactical means of conflict resolution. However, necessary detectand-avoid functionalities might only be available from $\mathrm{U} 4$ onwards [60]. When additionally accounting for delays in the implementation of U-space [9] there might be no regulation in effect allowing UAM flights in controlled airspace during the introduction phase of UAM, which is envisioned for airport shuttle services.

As a conclusion, the integration of UAS and UAM into the airspace structure around and at airports has been identified as an important subject, however so far not been addressed specifically. No provisions are made for IFR flights going beyond ICAO Doc 4444. The abovementioned statements, however, indicate that operations in CTR might become possible for VTOL vehicles, while operations near runways and approach paths will remain unfeasible. Therefore, assuming that entering an airport's CTR is possible, direct access to the airport terminal for UAM depends on the airport layout.
Closed airport layouts like the one of Munich Airport (MUC) with a terminal only reachable with runway or approach path crossing (see Fig. 2) cannot be accessed by VTOL vehicles, open airport layouts like in Düsseldorf (DUS) might, however, be able to be accessed. Here, only the entry into the CTR zone of the airport needs to be enabled for VTOL vehicles. It needs to be assumed, however, that most primary and secondary airports feature layouts where the terminal is not accessible to UAM.

An alternative solution might be UAM feeder flights to an airport access vertiport located inside the airport's CTR zone, however far from the runways, and being connected with the airport by high-speed suburban trains.

The resulting travel chain is depicted in Fig. 3. As compared to individual door-to-door transport by car, two changes of means of transport mean a significant loss of travel comfort. Travel times are sensible to vertiport access and process times in a range of one to $30 \mathrm{~min}[8,66]$ as well as waiting times for and operating frequencies of public transports. It seems questionable whether such UAM systems would achieve significant travel time reductions in the airport's current catchment area, high enough for justifying the associated loss of comfort. For long-range feeder traffic there might be benefits by expanding the airport's catchment area. Travel time advantages might only appear when there is a high level of congestion on competing transport systems, raising questions about revenue generation at non-peak times. Therefore, such a hybrid UAM system is expected to only show sustainable travel time reductions when serving regions without existing good connectivity towards the airport. This accounts for regions distant from public transport lines and high-speed road access, both inside cities as well as on a regional scale. The distance from the airport might

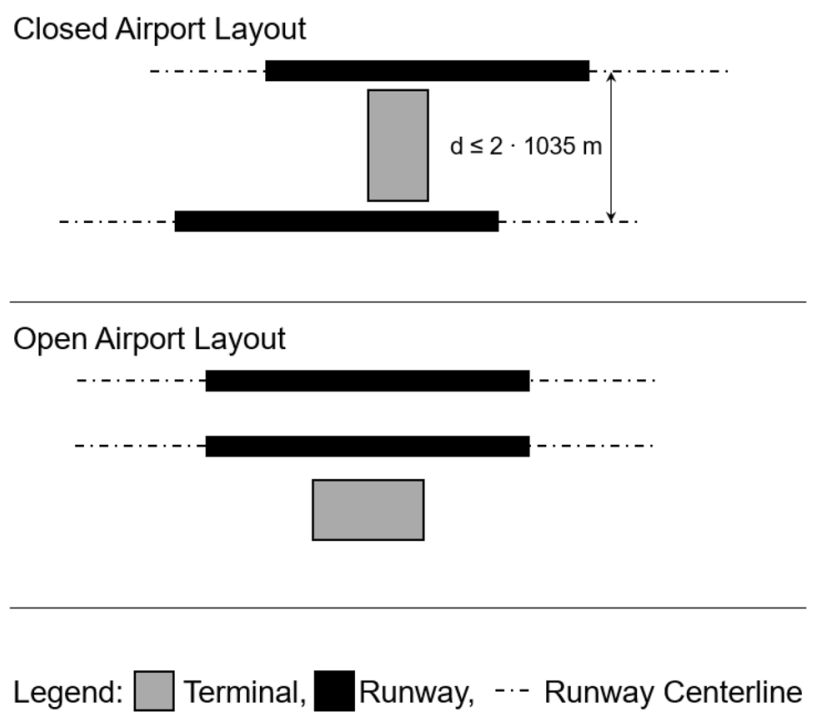

Fig. 2 Airport layouts, top: closed layout, bottom: open layout 


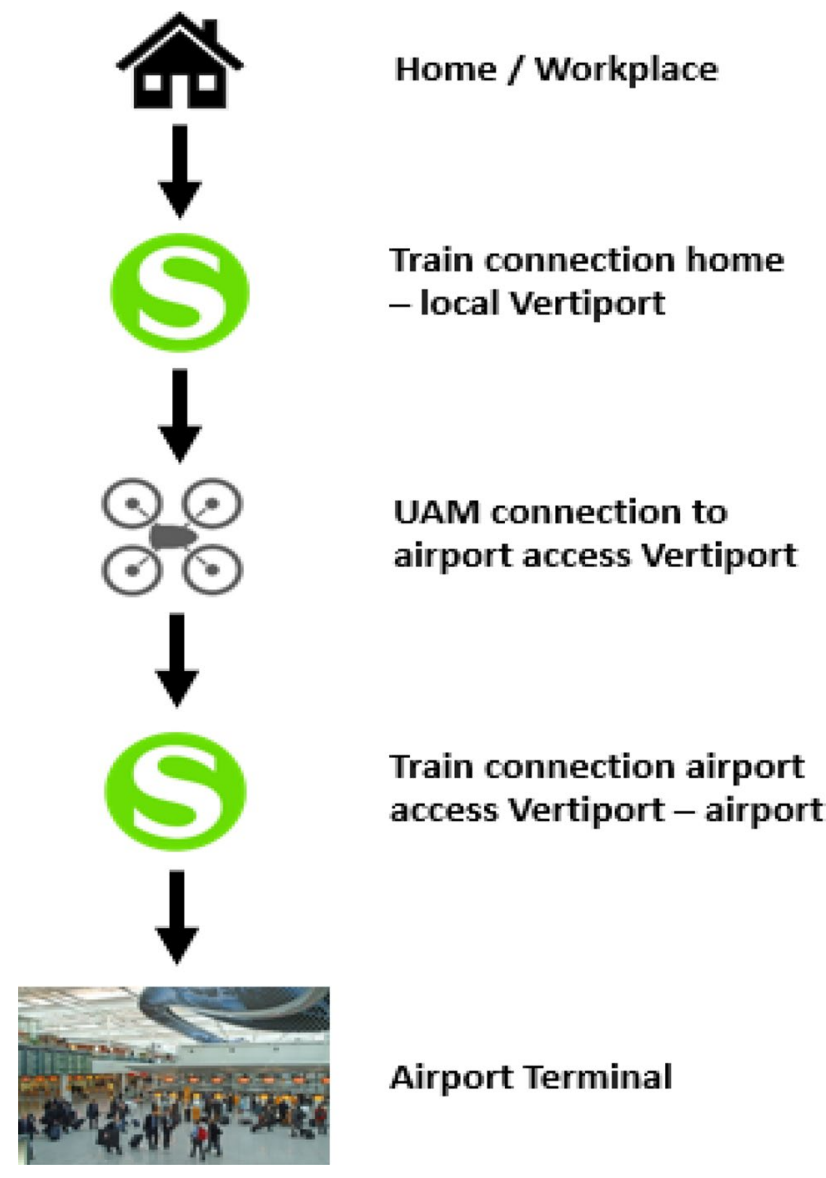

Fig. 3 Travel Chain for an airport access UAM service with airport access vertiport

even play a secondary role in this context. These points emphasize the sensitivity of travel times towards the journey's starting point, e.g., within a city, when assessing the benefits of UAM airport shuttles. This is opposed to reducing the city to a single, usually central point, as performed by many studies. More precise studies taking into account these local peculiarities use e.g., Agent-Based approaches, see for example [66].

Possible travel time benefits of the UAM system further are sensible to detours which might be required when overflying highly populated areas [67] and to waiting times due to vertipad occupancy if not sufficient landing pads are available. This might lead to a situation, where vertiports become a system bottleneck like airports for conventional aviation [14].

Conclusively, the success of airport shuttle services mainly depends on two aspects apart from vehicle powertrain development and demand. First, on the airport accessibility with current means of transport. UAM services can only be complementary to current transport where the latter does not function satisfactorily. Second, on the airport accessibility for UAM, mainly depending on the airport layout.
In combination with the described technical and regulatory hurdles and costs for such a service (e.g., precise navigation in all meteorological conditions), other operational concepts with less stringent requirements may be better suited during the introductory phase of UAM. Studies for example neglecting local peculiarities inside cities and regions as well as the described problems appearing from the airport layout (e.g., [19]), should therefore be evaluated critically.

\subsection{Company shuttle in joint venture operation}

It is likely that market demand for passenger UAM services arises from both the transport needs of individuals as well as from companies in their effort to optimize business travel and production processes [51].

In the following, a privately owned and cooperatively financed UAM business model is presented. The underlying idea is that individual companies as well as local joint bodies form an overarching consortium to operate a shared network of vertiports on their private premises only. Operation is thus relatively rigid carried out within a network of predefined and fixed routes. While such a system design primarily accelerates transportation between the companies' compounds, these are usually well connected to relevant traffic infrastructure hubs and are thus likely to enable an overall time- and resource-efficient onward transportation. The immediate effect of the concept will then be the accelerated transport of e.g. company employees, clients, fault clearance personnel or even urgent goods such as spare parts. Possible added value resulting from network effects between the participating companies are also taken into consideration. Benefits of initially pursuing private UAM operations as compared to a rather high-risk establishment of a comparable service in public space are highlighted in respect to legal and planning requirements as well as in respect to public acceptance.

At the initial stage of the Company Shuttle Service it is assumed that solely members of the operator consortium bear the operating costs while proportionally being entitled to use the service. However, a transport service provision to external customers such as enterprises or private individuals is considered to create a profitable business model in a second stage. The discussion part of the business models examines the possibility of an upscaling of the private network to public spaces, prospectively introducing municipalities as consortium members and addressing the general public as a new customer segment to create a strong regional UAM market lead.

\subsubsection{Company shuttle business model}

In the following, the business model of a joint venture Company Shuttle Service will be scrutinized in closer detail. 
4.2.1.1 Customer segment The business model primarily targets companies that aim to optimize their operational procedures or service offers by advancing their options on personnel and goods transportation. Thinking about the formation of an operator consortium, relevant members may be industrial players and service companies aiming for the time-efficient transport of company members on workrelated journeys between production sites, i.e., addressing the complete travel chain, as well as on business trips, i.e., addressing parts of a longer travel chain. Consortium members however, may as well assemble from across different sectors. For example, the hotel industry as well as conference and event venues can be considered.

For the future, the service may be opened for external companies that are not involved themselves in the operating consortium but are allowed to purchase capacities for their own employees to use the service. Depending on future scaling and capacity, the service could also become open for individual commuters via membership.

4.2.1.2 Value proposition The most important value proposition of such a service must be the accelerated transport of assigned personnel compared to a company's alternative transport methods such as company car fleets. As the envisioned service will have no interference with public ground transport, an increased reliability of the service and after all, high flexibility in operation is expectable for users. For the respective company employee, the travel time while using UAM can be used productively. The service may also be used by a company's clients or contractors such as hotel guests or conference participants. Depending on the VTOL vehicles, the transport of eligible and time-critical goods, e.g., documents, medical assets but also spare parts becomes feasible, thus minimizing production downtimes.

Overall, the UAM service increases the mobility of people and goods between different sites of one company or between various companies. This forms the basis for an increased exchange of information, stronger cooperation and even the implementation of sharing economy concepts between the consortium members [68]. For example, economic viability of the Company Shuttle Service may be realized if several companies decide to establish joint fault clearance services across their industrial sites. Shared warehouses or jointly used vehicle fleets for onward travels are also conceivable.

Furthermore, it should be considered that the establishment of a corresponding UAM service contributes to the value enhancement of existing infrastructures such as helicopter landing pads all while the shift from helicopters to VTOL vehicles could lead to operational cost savings in the future [32].

Further economic effects are indirect. It can be assumed that such a UAM service is highly representative, increasing a company's image and attractiveness in respect to customers and clients.

4.2.1.3 Channels In order for all participating companies to use the UAM service effectively, a common booking and billing platform is required. This has to be accessible by either the company's employee to directly book the service or by the relevant unit responsible for travel management. Anticipating the extension of the service to external privates or public individuals, it must be possible to book the service via a corresponding booking site or to integrate the UAM transport service option into external channels such as MaaS platforms.

4.2.1.4 Customer relationship The Company Shuttle service is initially based on the legal commitment of the operator consortium over a certain time period as well as on a common agreement for a fair distribution of costs and benefits. If the service is opened to external customers, the operator consortium evolves into a service provider and as such must guarantee a consistently high quality of service. Transparent routines must be developed to solve the consortium's transport demand conflicting with demand of external customers.

4.2.1.5 Key resources There are numerous circumstances that suggest initial UAM implementation in a private sector framework. One of the key resources to be mentioned in this respect are simplified legal requirements for infrastructure adoptions on the private ground as compared to public space. For example, UAM vertiports may face less constraints to be approved by the competent authorities and are thus likely to be constructed more time and cost-effectively. Additionally, their legal operation might be authorised with fewer constraints as well. Drawing on German law, indeed the operation of a vertiport on a company's premises will be closely subjected to the Occupational Health and Safety Act. However, as less local residents will be affected from the vertiports operation on private property, less constraint can be expected through the Environmental Protection Act. Moreover, it can be expected that a private Company Shuttle Service will be less dependent on societal acceptance compared to VTOL vehicles deployed in public spaces. That is since foremost company associates will be exposed to the negative implications of the UAM service such as noise during take-off and landing. The impact on the general public will be limited to safety and security risks as well as visual disturbances along flight paths.

A further added value of the concept is that numerous infrastructural requirements are already in place, decreasing the initial investment costs. The provision of a power supply to recharge the electrically powered VTOL vehicles can likely be made available on industrial 
sites. Additionally, the operating companies may facilitate existing security infrastructure on the company or factory premises for security check and customer handling.

Yet another key resource is the network integration of most companies to relevant traffic hubs and transportation infrastructure that currently allow for employees to commute to and from work. For customers using the Company Shuttle Service, this network integration fosters a timeand possibly resource-efficient onward transportation. In addition to that, customers might benefit from existing carpooling offers as well as car parking and charging facilities in proximity to the UAM infrastructure.

4.2.1.6 Key activity The key activity of the operator consortium is the scheduling, planning and supervision of its automated air transportation for people and goods between the participating compounds in accordance with the requirements of the air traffic control. The consortium must further provide and operate the relevant ground infrastructure.

Additionally, the operator should take responsibility to ensure a seamless onward journey after an VTOL vehicles flight towards the final destination which demands for a comprehensive management of supplement transportation capacities provided by the consortium members, e.g., common access to car fleets and chauffeur services, or external sources, e.g., using offers from a MaaS platform. If the service shall be opened to external parties, customer acquisition, marketing and consumer communication must be pursued.

4.2.1.7 Key partners Key partners of such a UAM service are the provider of the corresponding VTOL vehicles(s) including MRO. Besides that, established linkages to UTM and communication infrastructure providers are essential. Local authorities, airports or long-distance train stations as well as municipalities prospectively gain in importance as strategic key partners when strategically stretching the vertiport network into public space.

4.2.1.8 Cost structure Direct costs arise from leasing or purchasing the VTOL vehicless including MRO, energy supply as well as from the VTOL vehicles operation aligned to the ATC. Additional personnel costs for customer handling are necessary. Further costs are incurred for insurance and marketing purposes.

As argued, investments for setting up a private Company Shuttle Service are expected to be lower than introducing a service of the same size in public urban spaces. In the concept presented all costs are borne proportionately between the consortium members, which increases the chances of realization in comparison to a single-player approach. However, the set-up and qualification of the here presented private operator consortium demands initial resources. External consulting in setting up such a system might be necessary.

4.2.1.9 Revenue streams In this model of partial ownership, all consortium members bear the operating costs. Their level of engagement is proportional to usage rights. Supplemental income is generated by opening the service to external customers, i.e., companies or private individuals that are not part of the consortium and want to obtain contingents to use the Company Shuttle Service.

\subsubsection{Discussion}

Urban Air Mobility in public space will be confronted not just with planning and investment intensive infrastructure needs but also with uncertainty about public acceptance. The question of how under these circumstances UAM services can be introduced with assessable economic risk and then scaled up sustainably is as important as it is dubious. In this sense, the presented B2B approach may provide orientation. The advantage of a private space/private sector operator consortium is that investment and operating costs of such a UAM service can be distributed among several partners while adopting the service closely to the members' requirements.

However, the prerequisite for the establishment of such an operator consortium is that all parties involved can generate relevant added value from the use of VTOL vehicless. Consequently, initial considerations must be based on an inhouse process analysis. The key question is how UAM can be used meaningfully to optimize internal business and production procedures. Recent pilot projects show that drones can add value when used to transport time-critical medical samples between different company sites. Examples of when such an operational approach can reduce the travel time of people, e.g., of fault clearance personnel, are still pending. Corresponding applications are, however, being discussed in the context of rescue missions.

The second central question is whether such a business model can be used to achieve economically relevant synergy effects within a cross-company consortium. Can transport chains, for example for business trips, be optimised via a shared network of private vertiports? Where does UAM enable further potential to share resources or to contribute to their higher utilization within the consortia? The shared use of fault clearance personnel, shared warehouses or shared ground vehicle fleets are only approaches. Here too, process evaluations must be carried out between the involved consortium members.

Such an evaluation requires a creative but critical exchange between the potential associates. A working approach can be taken from the functioning of regional 
business networks whose aim is to identify and promote synergy effects in their network. Here, UAM as a physical component and in addition to digital networking offers new opportunities for innovation, for example as the basis for a sharing economy for goods and labour force.

Another relevant aspect for the assessment of the business model presented are legal framework conditions. Industrial sites in particular represent critical infrastructures. The extent to which the operation of UAM in the vicinity of such facilities will be possible is questionable as long as there are no binding regulations for the design of vertiports and their operation.

Either ways the implications of such a UAM service on the company sites employees must be considered. Occupational health and safety must be guaranteed, and measurements taken to adapt to the impacts of such an unprecedented transportation service. What is more, UAM as an expression of corporate hierarchy can have a positive, e.g., UAM as an attractive part of salary contracts, but also a negative, i.e., perceived elite-mobility, impact on a company's working culture. Hence, companies may apply co-design strategies to gain from their employees' knowledge on internal working process optimization potential through UAM as well as to get a comprehensive understanding of concerns regarding such a service [69].

It should be emphasized that the operational concept presented here is based on the existence of willing economic actors and is, within the presented conceptual approach, only feasible in economically strong regions. It has to be assessed case by case whether it is a region that already has an optimal, sustainable transport infrastructure or is suffering from traffic problems due to the great traffic density that would further justify such a UAM service.

Last but not least, the presented business model provides the chance for successive expansion of operation and sustainable economic growth through opening this rather exclusive mode of transportation for a private-public partnership. By introducing municipalities as new consortium members the UAM service can address transportation needs of municipal employees as well. From there, high chances are seen to get the service accessible for the general public as well in nearer future. A prerequisite for this is that the service has reached a relevant extension of network connections and that the local authorities as well as the public are convinced about the benefits and safety of the service. Based on these assumptions, public participation may be possible. By advancing from a solely private Company Shuttle Service to a private-public business concept, high chances are seen to create a strong market lead for the UAM operator in the respective region.

\subsection{Regional transportation service through public transport provider}

Often passenger VTOL vehicles are envisaged to alleviate congestion in urban settlements. Yet, this argument is debatable and other application cases might bring more societal benefits. In the following, the usage of VTOL vehicles for inter-city transport with a strong focus on connecting remote regions will be discussed. To diminish possible resulting segregation effects, with high-income people moving out of the city to attractive living areas, and the poorer staying inside the city because they just cannot afford to use UAM, the service is assumed to be operated by a public transport provider.

Increasing accessibility to remote regions and through that granting access to new labour markets, cultural events and medical care while promoting economic growth and fostering tourism is a chance for regions currently lagging behind.

The proposed UAM service could be similar to what can currently be seen in remote regions of the world without adequate road and rail access such as remote parts of Russia or services between different islands. These remote regions can only be connected to larger cities and necessary infrastructure through often subsidised services by helicopter and small aircraft. Through that, local governments often aim at strengthening such regions to prevent a further depopulation. Here, UAM might enable more flexible and popular services by offering on-demand solutions tailored for actual demand instead of scheduled options. This is possible due to the lower passenger capacities of VTOL vehicles as compared to e.g., Mi- 8 helicopters or An-2 biplanes used in Russia for such services. That way, UAM might help to stop the depopulation of remote areas and to make living in such areas more attractive, the same way as described above for the improvement of the attractiveness of living in suburbs of big cities which are poorly connected to the city centre with current means of transport.

Including UAM into the public transport system holds several advantages, the most obvious of them being transport fees that enable all parts of society to use that offer. Besides that, the approach can also foster a multi-modally integrated system set-up that, in the sense of environmental sustainability, operates on routes that do not lead to a cannibalization of existing public transport offers.

\subsubsection{Regional transportation service business model}

In the following, we present the business model envisioned for Regional Transportation Services through Public Transport Providers in more detail. 
4.3.1.1 Customer segment This business model targets a broad public from commuters to tourists including people travelling on their own as well as in a group. Prices are in a range that everyone can afford and all parts of society have access to the service. This is essential to find a social balance especially for innovative mobility offers. The service can support people living outside of cities to access labour markets as well as societal and cultural services.

The service is tailored to meet the mobility needs of all the population, explicitly including those with reduced mobility like disabled people or infants, making sure that the same standards are held that also apply for public busses and trains.

4.3.1.2 Value proposition The core of this business model is giving everyone access to mobility including the novel means of transport UAM. Offering UAM under the umbrella of public transport, gives all parts of society the opportunity to use inter-city air transport to travel to their work location, to visit friends and relatives or to travel to social and cultural venues. Besides that, installing the service also provides the opportunity for multi-usage of such systems to e.g., enable fast transport also in emergency cases possible due to existing infrastructure.

In addition to that, the public transport provider of a city can help foster the sustainability of UAM, as its overall objectives are to: (1) reduce transport-related emissions, (2) promote public health, and (3) reduce land consumption by choosing optimal means of transport.

The provider can define the role of UAM for local and regional mobility concepts of the future-in terms of internationally and nationally defined goals and agreements (UN Sustainable Development Goals, Paris Climate Agreement, the EU New Green Deal, German Climate Protection Plan, German Resource Efficiency Program).

Efficiently orchestrating UAM can improve environmental sustainability and reduce congestion of other modes of transport. System designs that e.g., introduce UAM as a feeder for the inner-city public transport could decrease car usage in cities.

Synergies stemming from integrated traffic control and aerial traffic observation could further strengthen this set-up.

4.3.1.3 Channels Customer communication will follow the already existing communication channels of the public transport provider. For UAM this will certainly have a focus on digital offers (website and app). Yet, service personnel and vending machines can ensure access for all parts of society. Considering the target groups, personnel at the vertiports is essential to also enable families with children and mobility impaired customers to access the service.
4.3.1.4 Customer relationship As this business model describes a settled transport provider to add UAM to its service offer, customer relationship is an interesting topic. While existing customers might like the add on and can benefit from additional services, new customers could also be attracted that have specific interest in this high speed service.

The grown relationship of trust between public transport provider and municipality and public will definitely benefit this business model approach. Yet, similar to the customer relationship with current public transport users direct interaction will be limited due to the sheer number of customers. Online booking as well as automated services will be predominant wherever possible.

In addition to that, a good customer relationship including nearly all parts of society could also benefit public acceptance, as one can assume that users are more willing to accept the service then non-users.

4.3.1.5 Key resources Some of the key resources are already existent within the operating company. Existing public transport stops and infrastructure may provide space for vertiports while at the same time ensuring short transfer times from UAM to other modes of transport. Besides that, traffic data and experience for transport operations within the respective city is existent. Digital infrastructure like websites and apps for booking and trip planning are already available and only require minor adaptations.

Yet of course, suitable vehicles and infrastructure would be required. In addition to that, staff has to be trained to enable safe and secure UAM operations.

4.3.1.6 Key activity The key activity of the public transport provider is to manage urban transport in an efficient and sustainable way. UAM would hereby be a part of the municipal services of general interest and a mobility option bringing about equivalent living conditions in terms of mobility, especially in previously underserved regions.

The public transport provider would operate ground infrastructure, plan, advertise, sell and operate the UAM flights and integrate the service into a multimodal transport system. Maintenance and overhaul will also be done in-house to decrease the time the UAM vehicles are grounded.

Additionally, concerted actions to provide public administrations with the know-how and tools to exploit the potential and opportunities of UAM can foster the opportunities of this business model approach.

4.3.1.7 Key partners Key partners of the service provider are local governments, supporting the novel mode of transport. Besides that, a strong linkage to UTM and communication infrastructure providers as well as to vehicle manufacturers is essential. By introducing special premium services 
for business travellers, corporate clients can also be won as key partners.

4.3.1.8 Cost structure Costs result from the actual operation of flights (energy consumption, cleaning, UTM fees, vehicle acquisition, maintenance and overhaul), as well as from in general offering the service (wages/salaries, insurance and infrastructure).

While infrastructure costs can be expected to be dominant cost drivers, public transport providers have years of experience building, operating and maintaining expensive transport infrastructure. The support from local governments decreases the risk for the operator, as long-term and robust investments through public budgets are possible.

4.3.1.9 Revenue streams Public transport in general is a non-self-financing service offer and therefore benefits from subsidies. Including UAM into the public transport system and focusing on routes that increase accessibility and foster economic development might lead to a need for subsidies for UAM as well. While lucrative routes could be selffinancing, other routes could be dependent on public aids.

Assuming UAM to nevertheless be a premium service could justify a surcharge for usage compared to other public transport fares. In addition to that, beneficiary models (participation of employers, housing associations) could be possible.

\subsubsection{Discussion}

Public transport, especially in Europe is a service of public interest which is massively subsidised by the government and often aims at transporting large numbers of people in the most efficient way, or specifically aims at providing transport service offers for all parts of society over the entire country. The discussions above show that in some parts this holds for UAM, in others it does not. UAM might be able to provide improved connectivity for remote regions and thus be very much in line with the idea of a service of public interest. Yet, UAM in urban and densely populated areas might attract large demand which it is not able to serve due to bottlenecks at vertiports and visual and noise annoyance of the public. With UAM not being a mass transport service, the service design has to be tailored to a promising operation which is more related to current on-demand services offered in less populated regions or off-peak.

In general, the incorporation of UAM into public transport offers opportunities and challenges. Advantages occur especially in the area of equity and equal living conditions. A publicly offered UAM service promises to be affordable to large parts of society and aims at specifically enhancing connectivity for those currently lagging behind. This opportunities for accessing novel trade and labour markets and thus, fostering economic development in these regions. In addition to that, the large customer segment is likely to increase public acceptance as the service is not perceived as solely targeting high income households. This is especially true if participatory approaches are applied when setting up the system.

The operation through the public transport provider also evades the risk of cherry picking through a private UAM operator. A situation in which services are only offered on profitable routes, taking demand from massively subsidised public transport routes. This point was already brought up by Straubinger and $\mathrm{Fu}$ [70], who also propose network designs in favour of UAM and public transport integration. Distinguishing between UAM routes that serve as a feeder for the inner-city public transport system and UAM routes that provide a connection on routes that are currently not well served or not served at all by public transport. These network design approaches might therefore be relevant for this business model.

Yet, including a transport service into the public transport portfolio, that is not suitable for mass transport, that has high operating and fix costs and that's operation is rather different compared to other modes of public transport also poses difficulties. This is especially the case as long-run impacts are still hard to foresee. For example, a large-scale introduction of UAM with rather low fares and thus relatively high modal split could even provoke relocation. Rothfeld et al. [13] have shown that research in this area is still limited. Therefore, the impact of high travel speeds in the context of constant travel times could even foster urban sprawl, which then would lead to additional travel demand in total. In addition to that, UAM might not be in line with overall transport policy goals that have a strong emphasis on environmental friendly travel behaviour. A thorough analysis has to be conducted to identify routes on which UAM offers advantages also in energy consumption to foster political will to support on-demand aerial mobility, especially as part of the public transport system. Additionally synergy potential for cargo delivery is limited for this business model approach. Besides that, legislation for public transport service uptake is strict and including UAM into the service offer might require amendments that again build on political will as well as the public's support.

Yet, integrating other modes of transport into public transport service offers is very much in line with current tendencies towards MaaS. The public transport provider in Berlin is now operating ride-sharing services called Ber1König on a test basis to better understand the option that digitalisation can have for the sector. In Munich the public transport provider is partnering with the private e-scooter service TIER mobility and offers the e scooter service on their mobility platform. These examples show that both, self-operated MaaS as well as public-private-partnerships 
for MaaS are viable and innovative approaches for public transport providers. Yet, of course, integrating UAM into a public transport service poses vast difficulties that are not comparable to the services mentioned before. These hurdles reach from cost over safety to public acceptance and might prevent the introduction of such services.

Additionally, innovative mobility solutions provided and supported by local authorities are a promising marketing factor for a region, as innovation is a trigger for companies, as well as private households.

\section{Conclusion}

As VTOL vehicles concepts become increasingly mature, the potential application spectrum of these vehicles is expanding. At the same time, the picture becomes more certain on how an operating environment must be designed in which commercial UAM services can be offered in the future. However, how this technological innovation can positively influence our societies and at the same time allow for economically viable business cases has rarely been investigated from a scientific perspective. Based on three diverging approaches (Airport-Shuttle/Company Shuttle/Public Transportation) the article at hand opens up the space for a critical, open minded and value-led discussion on business model options in the field of passenger UAM.

The discussion must thereby inevitably be placed within the context of current scientifically anticipated barriers for the implementation of UAM as a future means of transportation. Political steering tasks, technical, infrastructural and societal aspects will have a direct impact on the economic viability of air taxi services. Additionally, high emphasis must be given on economical consideration towards passenger UAM. In this paper, central thoughts on the current state of market development and expectations on market size are elaborated. Possible operator models and customer segments are compiled. In summary, this allows for the overall system view that is essential for a credible and meaningful assessment of the business models, which in this article are conceptualised using the business model canvas approach of Osterwalder and Pigneur [6].

The discussion of an airline operated Airport Shuttle has shown that an operational concept for UAM does not only require a valid business case, expressing a reliable customer demand, but also highly depends on a comprehensive view on the overall operational system. For customers this includes the vertiport's accessibility from a relevant area of interest compared to current competing means of transport. Even inside a city there might be significant discrepancies for this factor for different quarters, with many origin and destination pairs having no travel time advantages due to the UAM service introduction. In addition to that, due to interference with conventional air traffic at the airport, mostly at big hub airports with closed runway layouts, UAM services relate to inacceptable reductions in conventional runway capacity. As argued, regulatory and technological advancements associated with the introduction of UAM are not expected to solve these problems. Alternatives might lay in airport access vertiports inside the airport CTR zone. However, these require an additional change in the means of transport for customers, coming along with deteriorations in travel time and comfort, the two main KPIs of the business model. Nevertheless, such airports with an open runway layout might be able to accommodate functioning UAM shuttle systems in the future. Finally, as airlines have been exemplified as operators for the presented business model, their core competences such as inner-airport integration and experience in customer handling will likely fall back in respect to a now needed consolidation due to the COVID-19 crisis.

With the Company Shuttle Services in joint venture operation a so-far unpublished business concept is presented. The underlying idea is that individual companies as well as local joint bodies form the consortium to operate a shared network of vertiports solely on their private premises. While such a service primarily accelerates the (inter-) regional transport of people between the companies' compounds, these are usually well connected to relevant traffic infrastructure hubs to enable time- and resource-efficient onward transportation. As is shown clearly, the concept offers considerable advantages compared to an implementation approach of UAM in public space regarding planning, infrastructural and societal requirements. However, the key discussion points of the presented concept are how UAM can be used to meaningfully optimize a company's business travel and production procedures as well as whether such a business model can be used to achieve economically relevant synergy effects within the proposed cross-company consortium, too. The business model scrutinizes further on how the provision to external customers such as enterprises or private individuals can lead to profitable operation. Finally, the presented business model considers the chance to successively expand from a solely private endeavour to a private-public transport service, introducing municipalities as new consortium members and potentially expanding the service to the general public as well. Emphasising on this phase approach, high chances are seen to create a strong market lead for UAM in the respective regions.

As clearly shown the approach of integrating UAM into the Public Transport system poses both advantages and disadvantages. UAM services operated by a public transport provider promise to be at costs that make the mobility offer accessible for the broad public. This in return could significantly increase public acceptance as UAM will not be perceived as a transport service only for high income households. Additionally, an efficient integration with public 
transport can decrease negative environmental externalities and support sustainable mobility planning. On the contrary, the application scenarios for UAM have to be studied carefully to make sure that UAM is the most beneficial mode for the specific use-case. In general, UAM operation through the public transport provider could be a promising approach, yet, especially in the beginning the related risks could be too high to be eligible for public spending and subvention. Despite, during later stages of development this business model could especially be promising in areas with geographical characteristics that make ground-based transport less attractive.

The authors of this article are aware that not all influencing factors are comprised in the assessment of the respective business models and that several business model approaches have stayed unconsidered. Business model development for UAM remains an iterative process, aiming to increasingly replace hypotheses with empirical facts gathered over time. However, the remarks up to this point clearly show that the debate on technically verifiable, economically viable and socially meaningful UAM business models is far from an end. Only a critical discussion of UAM business models can eventually lead to a growing acceptance of the economic use of UAM in public airspace and to further investments necessary for its implementation.

\section{References}

1. Shamiyeh, M., Bijewitz, J., Hornung, M.: A Review of recent personal air vehicle concepts. In: Aerospace Europe 6th CEAS Conference (2017)

2. Shamiyeh, M., Rothfeld, R., Hornung, M. (eds.): A Performance Benchmark of Recent Personal Air Vehicle Concepts for Urban Air Mobility. In: The International Council of the Aeronautical Sciences (2018)

3. Cohen, B., Kietzmann, J.: Ride on! Mobility business models for the sharing economy. Organ. Environ. 27(3), 279-296 (2014)

4. Liao, F., Molin, E., Timmermans, H., van Wee, B.: Consumer preferences for business models in electric vehicle adoption. Transp. Policy 73, 12-24 (2019)

5. Stocker, A., Shaheen, S.: Shared automated vehicles: review of business models. Discussion Paper, 2017-09. ITF OECD (2017)

6. Osterwalder, A., Pigneur, Y.: Business Model Generation. A Handbook for Visionaries, Game Changers, and Challengers. Wiley, Hoboken (2010)

7. Kellermann, R., Biehle, T., Fischer, L.: Drones for parcel and passenger transportation: a literature review. Transport. Res. Interdiscip. Perspect. 4, 100088 (2020)

8. Straubinger, A., Rothfeld, R., Shamiyeh, M., Büchter, K.-D., Kaiser, J., Plötner, K.O.: An overview of current research and developments in urban air mobility - setting the scene for UAM introduction. J. Air Transp. Manag. 87, 101852 (2020)

9. SESAR Joint Undertakin: European ATM master plan: roadmap for the safe integration of drones into all classes of airspace (2018)

10. SESAR Joint Undertaking: Supporting safe and secure drone operations in Europe. A preliminary summary of SESAR U-space research and innovation results (2017-2019) (2020)
11. SESAR Joint Undertaking: Initial view on principles for the U-space architecture (2019)

12. Vascik, P.D., Hansman, R.J.: Development of Vertiport Capacity Envelopes and Analysis of Their Sensitivity to Topological and Operational Factors. In: AIAA Scitech 2019 Forum, p. 409 (2019)

13. Rothfeld, R., Straubinger, A., Fu, M., Al Haddad, C., Antoniou, C.: Urban air mobility. In: Antoniou, C., Efthymiou, D., Chaniotakis, E. (eds.) Demand for Emerging Transportation Systems, pp. 267-284. Elsevier, Amsterdam (2019)

14. Mueller, E.R., Kopardekar, P.H., Goodrich, K.H.: Enabling airspace integration for high-density on-demand mobility operations. In: 17th AIAA Aviation Technology, Integration, and Operations Conference, p. 29. American Institute of Aeronautics and Astronautics, Reston (2017)

15. Geister, D., Korn, B.: DLR Blueprint - Concept for Urban Airspace Integration. Integrating UAS into the future aviation system. A flexible approach enabling large-scale UAS operations. Institute of Flight Guidance (2017)

16. Heutger, M., Kückelhaus, M.: Unmanned aerial vehicles in logistics. A DHL Perspective on Implications and Use Cased for the Logistics Industry (2014)

17. Skorup, B.: Auctioning Airspace. SSRN J. 4, 4 (2018)

18. Thipphavong, D.P., Apaza, R., Barmore, B., Battiste, V., Burian, B., Dao, Q., Feary, M., Go, S., Goodrich, K.H., Homola, J., Idris, H.R., Kopardekar, P.H., Lachter, J.B., Neogi, N.A., Ng, H.K., Oseguera-Lohr, R.M., Patterson, M.D., Verma, S.A.: Urban air mobility airspace integration concepts and considerations. In: 2018 Aviation Technology, Integration, and Operations Conference, p. 2018. American Institute of Aeronautics and Astronautics, Reston, Virginia (2018)

19. Porsche Consulting: The future of vertical mobility. Sizing the market for passenger, inspoection and goods services until 2035 (2018)

20. Roland Berger: Urban air mobility. The rise of a new mode of transportation (2018)

21. European Commission: Ein neues Zeitalter der Luftfahrt: Öffnung des Luftverkehrsmarktes für eine sichere und nachhaltige zivile Nutzung pilotenferngesteuerter Luftfahrtsysteme (2014)

22. Du, H., Heldeweg, M.A.: Responsible design of drones and drone services—a synthetic report. SSRN J. 14(1), 286 (2017)

23. Christen, M., Guillaume, M., Jablonowski, M., Lenhart, P., Moll, K.: Zivile Drohnen-Herausforderungen und Perspektiven, 1st edn. TA-SWISS, Zürich (2018)

24. Chamata, J., Winterton, J.: A conceptual framework for the acceptance of drones. ITMR 7(1), 34 (2018)

25. Otto, A., Agatz, N., Campbell, J., Golden, B., Pesch, E.: Optimization approaches for civil applications of unmanned aerial vehicles (UAVs) or aerial drones: a survey. Networks 72(4), 411-458 (2018)

26. Grunwald, A.: Responsible innovation: bringing together technology assessment, applied ethics, and STS research. Enterp. Work Innov. Stud. 7, 9-31 (2011)

27. Lidynia, C., Philipsen, R., Ziefle, M.: The sky's (not) the limitinfluence of expertise and privacy disposition on the use of multicopters. In: Chen, J. (ed.) Advances in Intelligent Systems and Computing, pp. 270-281. Springer, Cham (2018)

28. Clothier, R.A., Greer, D.A., Greer, D.G., Mehta, A.M.: Risk perception and the public acceptance of drones. Risk Anal. 35(6), 1167-1183 (2015)

29. Dannenberger, N., Schmid-Loertzer, V., Liliann Fischer, Schwarzbach, V., Kellermann, R., Biehle: Traffic solution or technical hype? Representative population survey on delivery drones and air taxis in Germany (2020)

30. Bundesministerium für Verkehr und digitale Infrastruktur: Umgang mit Drohnen im deutschen Luftraum: Verkehrspolitische 
Herausforderungen im Spannungsfeld von Innovation, Safety, Security und Privacy (2019)

31. Nentwich, M., Horváth, D.: Delivery drones from a technology assessment perspective (2018)

32. Wynsberghe, A., Soesilo, D., Thomasen, K., Sharkey, N.: Report: Drones in the Service of Society (2018)

33. Otto-Zimmermann, K., Roeßiger, F.: Drohnen-Ihre Invasion in den städtischen Raum hat begonnen (2018)

34. Al Haddad, C., Chaniotakis, E., Straubinger, A., Plötner, K., Antoniou, C.: Factors affecting the adoption and use of urban air mobility. Transp. Res. A 132, 696-712 (2020)

35. Schuchardt, B., Lehmann, P., Nieuwenhuizen, F., Perfect, P.: Deliverable D6.5 final list of desirable features/options for the PAV and supporting systems. https://elib.dlr.de/136822/ (2015). Accessed 7 April 2021

36. Duwe, D., Keicher, L., Ruess, P., Klausmann, F.: Quo vadis 3D mobility. Technological readiness, urban and rural use cases $\&$ urban integration of flying cars and passenger drones (2019)

37. Kitonsa, H., Kruglikov, S.: Significance of drone technology for achievement of the United Nations sustainable development goals. R-Economy 4, 115-120 (2018)

38. Singhal, G., Bansod, B., Mathew, L.: Unmanned aerial vehicle classification, applications and challenges: a review (2018)

39. Biehle, T.: Ständige Überwachung-Militärische Interessen im zivilen Drohnenmarkt Europas. PROKLA. Zeitschrift für Kritische Sozialwissenschaft 50(201), 665-680 (2020)

40. Doole, M., Ellerbroek, J., Hoekstra, J.: Drone Delivery: Urban airspace traffic density estimation. Eight SESAR Innovation Days Conference (2018)

41. Horvath \& Partners: Business between sky and earth-Assessing the Market Potential of Mobility in the 3rd Dimension. https://www. horvath-partners.com/de/media-center/studien/urban-air-mobilitystudy-report-2019/ (2019). Accessed 7 April 2021

42. Yedavalli, P., Mooberry, J.: An assessment of public perception of urban air mobility (UAM) (2019)

43. Rao, B., Gopi, A.G., Maione, R.: The societal impact of commercial drones. Technol. Soc. 45(4), 83-90 (2016)

44. Kreimeier, M., Stumpf, E.: Market volume estimation of thin-haul On-demand air mobility services in Germany. In: 17th AIAA Aviation Technology, Integration, and Operations Conference, p. 41. American Institute of Aeronautics and Astronautics, Reston (2017)

45. Syed, N., Rye, M., Ade, M., Trani, A., Hinze, N., Swingle, H., Dollyhigh, S., Smith, J.C., Marien, T.: preliminary considerations for odm air traffic management based on analysis of commuter passenger demand and travel patterns for the Silicon valley region of California. In: 17th AIAA Aviation Technology, Integration, and Operations Conference. American Institute of Aeronautics and Astronautics, Reston (2017)

46. Decker, M., Fleischer, T., Meyer-Soylu, S., Schippl, J.: Personal air vehicles as a new option for commuting in Europe: vision or illusion? The 41st European Transport Conference, pp. 1-20 (2013)

47. Hansman, J., Vascik, P.: operational aspects of aircraft-based on-demand mobility aircraft-based on-demand mobility. 2nd ondemand mobility and emerging aviation technology roadmapping workshop 156 (2016)

48. Nneji, V.C., Stimpson, A., Cummings, M., Goodrich, K.H.: Exploring concepts of operations for on-demand passenger air transportation. In: 17th AIAA Aviation Technology, Integration, and Operations Conference. American Institute of Aeronautics and Astronautics, Reston (2017)

49. Straubinger, A., Kluge, U., Fu, M., Al Haddad, C., Ploetner, K.O., Antoniou, C.: Identifying demand and acceptance drivers for user friendly urban air mobility introduction. In: Müller, B., Meyer, G. (eds.) Lecture Notes in Mobility, pp. 117-134. Springer, Berlin (2020)
50. Kluge, U., Paul, A., Ureta, H., Ploetner, K.O.: Profiling future air transport passengers in Europe. In: European Commission (ed.) 7th Transport Research Arena TRA 2018, Vienna, Austria (2018)

51. Reichmuth, J., Grimme, W., Berster, P., Gelhausen, M.: Analyses of the European air transport market—airport accessibility in Europe. Topical Report, Deutsches Zentrum für Luft- und Raumfahrt (DLR), (2010

52. Kluge, U., Paul, A., Urban, M., Ureta, H.: Assessment of passenger requirements along the D2D air travel chain. In: Müller, B., Meyer, G. (eds.) Lecture Notes in Mobility, pp. 255-276. Springer, Cham (2019)

53. Haidari, L.A., Brown, S.T., Ferguson, M., Bancroft, E., Spiker, M., Wilcox, A., Ambikapathi, R., Sampath, V., Connor, D.L., Lee, B.Y.: The economic and operational value of using drones to transport vaccines. Vaccine 34(34), 4062-4067 (2016)

54. Shaheen, S.A., Cohen, A.P., Broader, J., Davis, R., Brown, L., Neelakantan, R., Gopalakrishna, D., ICF, University of California, Berkeley. transportation sustainability research center: mobility on demand planning and implementation: current practices, innovations, and emerging mobility futures, FHWA-JPO-20-792. United States. Department of Transportation. Intelligent Transportation Systems Joint Program OfficeUR (English) (2020)

55. Lemmer: Neue autoMobilität. Kooperativer Straßenverkehr und intelligente Verkehrssteuerung für die Mobilität der Zukunft (2019)

56. Booz-Allen and Hamilton Inc.: Urban Air Mobility (UAM) Market Study (2018)

57. Volocopter: Mobility of the Future: Fraport and Volocopter Are Developing Airport Infrastructure and Passenger Processes for Air Taxi Services (2019)

58. Fu, M., Rothfeld, R., Antoniou, C.: Exploring preferences for transportation modes in an urban air mobility environment: Munich case study. Transp. Res. Rec. 2673(10), 427-442 (2019)

59. International Civil Aviation Organization (ICAO): Doc 4444: Air Traffic Management-Procedures for Air Navigation Services. Sixteenth Edition (2016)

60. SESAR Joint Undertaking: CORUS-U-space concept of opertaions enhanced overview (2019)

61. SESAR Joint undertaking: U-space blueprint (2017)

62. Federal Aviation Administration: Unmanned Aircraft System (UAS) Traffic Management (UTM) Concept of Operations v2.0 (2020)

63. SESAR Joint Undertaking: European drones outlook study - unlocking the value for Europe (2016)

64. EASA, Eurocontrol: UAS ATM Integration. Operational Concept (2018)

65. International Civil Aviation Organization (ICAO): ICAO Long-term traffic forecasts passenger and cargo (2018)

66. Rothfeld, R., Balac, M., Ploetner, K.O., Antoniou, C. (eds.): Agentbased simulation of urban air mobility. 2018 Modeling and Simulation Technologies Conference (2018)

67. Rothfeld, R., Fu, M., Antoniou, C.: Analysis of urban air mobility's transport performance in munich metropolitan region. mobil.TUM, Munich (2019)

68. Richardson, L.: Performing the sharing economy. Geoforum 67, 121-129 (2015)

69. Biehle, T., Kellermann, R.: Mind the gap: concepts and pathways for a societally acceptable future of UAS in Europe. White Paper, Sky Limits (2019)

70. Straubinger, A., Fu, M.: Identification of strategies how urban air mobility can improve existing public transport networks. In: mobil. TUM, pp. 1-3, Munich (2019)

Publisher's Note Springer Nature remains neutral with regard to jurisdictional claims in published maps and institutional affiliations. 